\title{
Sugestões para Criação de um Instituto Brasileiro de Planejamento e Desenvolvimento
}

\author{
Jõ̃o JoRGE DA CUNHA
}

$\mathrm{E}$

XISTem, no Brasil, 10 pólos de desenvolvimento, onde se concentram $20 \%$ da população total (estimativas de 1967, IBGE e de 1968, para o Distrito Federal, IBRAPLAN):

\begin{tabular}{|c|c|c|}
\hline São Paulo . . & 5.383 .194 & habitante \\
\hline Guanabara .......... & 4.031 .289 & \\
\hline Belo Horizonte ...... & 1.091 .972 & \\
\hline Recife .............. & 1.056 .100 & \\
\hline Pôrto Alegre .. & 889.210 & $》$ \\
\hline Salvador ...... & 858.730 & \\
\hline Fortaleza & 794.078 & $"$ \\
\hline Belém .. & 546.339 & $"$ \\
\hline Curitiba $\ldots \ldots \ldots \ldots$ & 575.889 & $"$ \\
\hline Distrito Federal ...... & 421.000 & $"$ \\
\hline
\end{tabular}

Através dêsses pólos de desenvolvimento atuaria o IBRAPLAN, alcançando cêrca de 200 regiões-programa.

Em cada pólo de desenvolvimento poderiam se concentrar de 50 a 100 Mestres em Planejamento Integrado e em cada região-programa, de 4 a 10 Especialistas em Planejamento Integrado. Teríamos, assim, necessidade de preparar de 500 a 1.000 Mestres em Planejamento Integrado e de 800 a 2.000 Especialistas em Planejamento Integrado nos próximos 3 anos.

Essa atividade seria complementada com a preparação de técnicos auxiliares, em cursos de treinamento intensivo, nas regiõesprograma.

A todos êsses profissionais seriam oferecidas garantias de trabalho bem remunerado, de acôrdo com o aproveitamento nos cursos e com as disponibilidades financeiras provocadas pelo planejamento. 
Êsse programa representa um grande passo na absorção de mão-de-obra qualificada. Em publicação recente, o "Jornal do Brasil" focalizou êsse problema angustiante que é o da oportunidade de trabalho para os profissionais que terminam os cursos universitários.

"Enquanto mais de 340 mil jovens estão ingressando êste ano (1969) nos 1.592 cursos de nivel superior, diz a reportagem, apenas cêrca de $28 \mathrm{mil}$ dos $258 \mathrm{mil}$ matriculados nas faculdades conseguiram concluir os cursos. Dêstes 28 mil mais de 10 mil jovens não conseguiram exercer a profissão.

E apresenta outros números significativos: dos 3.979 jovens formados em Administração de Emprêsas, em 1967, sòmente 72 conseguiram emprêgo e estão se dedicando à profissão.

Na Engenharia a situação é também grave: 3.704 dos 30.880 matriculados na última série concluíram o curso, mas sòmente 1.908 estão conseguindo exercer a profissão.

Dos 41.800 alunos matriculados no último ano de Direito nas 87 escolas do País, 5.229 conseguiram obter o diploma e 3.217 estão se dedicando à profissão; dos 1.977 médicos formados em 1967. entre os 20.448 matriculados, 1.637 estão empregados ou exercendo a profissão em caráter autônomo. Formaram-se 1.436 dentistas e 1.085 se encontram em atividade.

Há uma necessidade imperiosa, portanto, de criar condições para o aproveitamento dessa excelente mão-de-obra. A única solução racional nos parece $\operatorname{ser}$ a da interiorização do profissional com remuneração condigna, através de um sistema nacional de desenvolvimento local integrado. $O$ planejamento integrado, nos vários niveis, nacional, regional, estadual e local, realizado através de Escritórios de Planejamento Integrado terá possibilidades de absorver um grande número de profissionais no planejamento e em decorrência dos processos de desenvolvimento provocados pelo planejamento.

\section{Custos}

Segundo cálculos que elaboramos serão necessários ..... NCr\$ 20.000,00 para a formação de um Especialista em Planejamento Integrado, incluindo-se os trabalhos de organização dos Escritórios de Planejamento Integrado e os serviços de assessoria durante a execução do Plano Diretor de Desenvolvimento Local Integrado. 
Os trabalhos do IBRAPLAN seriam financiados pelo SERFHAU, por solicitação das Entidades interessadas (regional, estadual, local), permitindo, mesmo aos pequenos municipios, a utilização de profissionais altamente qualificados.

\section{NECESSIDADE DE PLANEJAMENTO INTEGRADO}

São Paulo é o único Estado cujos municípios estão providenciando seus planos diretores de desenvolvimento integrado por fôrça da Lei Orgânica dos Municípios (Lei n 9.842, de 19-9-67) que estabelece:

“Art. 79. O Municipio elaborará o seu Plano Diretor de Desenvolvimento Integrado, considerando em conjunto os aspectos físicos, econômicos, sociais e administrativos, nos seguintes têrmos:

I - fisico-territorial - com disposições sôbre o sistema viário urbano e rural, o zoneamento urbano, o loteamento urbano ou para fins urbanos, a edificação e os serviços públicos locais;

II - econômicos - com disposições sôbre o desenvolvimento econômico do Município;

III - social - com normas destinadas à promoção social da comunidade local e ao bem-estar da população;

IV - administrativo - com normas de organização institucional que possibilitem a permanente planificação das atividades municipais e sua integração nos planos estadual e nacional.

Parágrafo único. - Nenhum auxílio financeiro ou empréstimo será concedido pelo Estado ao Município que não possuir Plano Diretor de Desenvolvimento Integrado, aprovado, após 3 (três) anos da vigência desta lei.

Art. 80. O Município elaborará as normas de edificação, de zoneamento e de loteamento urbano ou para fins urbanos, atendidas as peculiaridades locais e a legislação federal e estadual pertinentes."

Acontece, entretanto, que o preço cobrado pelas firmas especializadas é tão elevado que a maioria dos municípios se encontra impossibilitada de contratar os serviços de elaboração de planos diretores de desenvolvimento integrado.

Nos outros Estados estão sendo feitos, principalmente nos municipios das Capitais, planejamentos setoriais, de acôrdo com as conveniências das firmas contratadas, destacando-se, na suá maioria, os aspectos urbanísticos. 
No Congresso Hispano-Luso-Americano-Filipino de Municipios, reunido em Brasília, em novembro de 1966, já se destacava a necessidade de uma política de planejamento do desenvolvimento local integrado "visto que, ao nível municipal, se concretizam muitas medidas e ações que conduzem ao desenvolvimento".

Rubens Pereira, em recente trabalho publicado na Revista de Administração Pública (No 1, 1968) estabelece os seguintes critérios para o planejamento urbano no Brasil.

19) A unidade de Planejamento, denominada Região-Programa, poderá ser:

a) uma micro-região homogênea (do tipo de uma pequena bacia fluvial, faixa litorânea etc.), definida de acôrdo com trabalho EPEA-CNG; essa região deverá conter, pelo menos, um pólo urbano (centro de polarização), com população superior a 50.000 habitantes;

b) uma área metropolitana, incluindo-se, na região-programa dêstes casos, tôda a zona de influência da metrópole em questão. A definição desta região também deverá ser feita com base no trabalho EPEA-CNG.

2:) Potencial de desenvolvimento - Definidas as regiõesprograma, de acôrdo com os estudos EPEA-CNG, e estabelecido o montante inicial que se pretende investir em planejamento local, será necessário selecionar algumas regiões-programa. Serão prio ritárias aquelas que apresentem maiores potenciais de desenvolvimento e capacidade de, com relativamente poucos recursos, abrir perspectivas para o desenvolvimento de áreas interiores à região, ou mesmo, áreas contínuas à regiäo.

39) Distribuição Regional Equilibrada - Tal critério proporcionará a realização de experiências iniciais diversificadas, permitindo sua utilização imediata nas diferentes regióes do Estado ou do Pais.

4\%) Existência de pré-condições institucionais - Observados os três critérios anteriores, um $4^{\circ}$ critério poderá pesar, ainda, na escolha da Região-Programa. Trata-se da existência de précondições institucionais na região, isto é, a existência de planos ou escritórios de planejamento, o interêsse dos governos locais, etc.

\section{SituaÇão ATUAL DO PLANEJAMENTO URBȦNO NO BRASIL}

Segundo levantamento feito por Rubens Pereira, apenas $11,6 \%$ das cidades brasileiras possuem órgãos de planejamento e urbanismo. Em verificação mais acurada, entretanto, constata 
o mesmo autor que essa percentagem é otimista, pois "a percentagem de planos-diretores é maior que aquela de órgãos de planejamento e urbanismo. Tal fato denota a tendência que têm as Prefeituras brasileiras de contratar a feitura do Plano com escritórios alheios ao seu corpo administrativo, sem a preocupação de organizar o órgão local de planejamento."

A região sul (principalmente o Estado do Rio Grande do Sul) possui a maior percentagem de órgãos de planejamento $c$ urbanismo do País; as regiões menos desenvolvidas do Norte, Nordeste e Centro-Oeste são as que têm menor percentagem de órgãos especificos e normas de urbanismo do País, conforme se verifica na relação seguinte:

Municipios que elaboraram planos-diretores em moldes mais ou menos atualizados:

Região Extremo-Sul (Rio Grande do Sul, Paraná, Santa Catarina) -70 municípios.

Região Sudeste (São Paulo, Minas Gerais, Guanabara, Rio de de Janeiro, Espírito Santo) - 30 municípios.

Região Centro-Oeste (Goiás, Mato Grosso, Distrito Federal) - Menos de 5 municípios.

Região Nordeste (Bahia, Sergipe, Alagoas, Pernambuco, $\mathrm{Pa}$ raíba, Rio Grande do Norte, Ceará, Piauí, Maranhão) - Menos de 10 municípios.

Região Norte (Amazonas, Pará, Acre e Territórios Federais) - Menos de 5 municípios.

Verifica-se, assim, que a cifra de $11,6 \%$ se reduz a $4 \%$ Mas, quando se procura verificar quantos dêsses municípios possuem planos bem elaborados e exeqüiveis e órgãos de planejamento local organizados em bases modernas, restam, apenas, 10 ou 12 .

"A grande maioria das áreas urbanas do País, diz Rubens Pereira (op. cit.), continua a crescer desordenadamente sem obedecer às mais elementares normas que a técnica moderna pode colocar à disposição dos administradores, acarretando, conforme já ficou evidenciado anteriormente, um tremendo e inútil ônus para o investimento público, além dos enormes inconvenientes de caráter social que a urbanização acarreta."

\section{AVALIAÇÃO DOS PLANOS MUNICIPAIS}

A falta de realismo é a principal caracteristica das experiências de planejamento local no Brasil. Os planos são, em geral, 
eminentemente técnicos, mas "não traduzem a realidade sócioeconômica do Municipio, nem consideram as estruturas politicoadministrativas locais que, em última análise, serão responsáveis. pela execução dos planos." (Rubens Pereira). radas:

As causas dessa falta de realismo podem ser assim enume-

$1^{\text {a) }}$ Poucos municipios tiveram, até hoje, oportunidade de urganizar um bom escritório de planejamento;

$2^{\text {a }) ~ A ~ m a i o r i a ~ d o s ~ p l a n o s ~ s a ̃ o ~ s e t o r i a i s, ~ e n f a t i z a n d o ~ o s ~ a s-~}$ pectos físicos, sem a participação de economistas, cientistas sociais e técnicos em administração pública, isto é, não são planos integrais;

$3^{\text {a) }}$ Os planos não se integram com os reais interêsses e aspirações das comunidades cujo desenvolvimento pretendem;

4a) Ausência de um programa de treinamento de técnicos em planejamento integrado;

5 a) Falta de entrosamento entre os planos de desenvolvimento nacional, regional, estadual e local.

\section{FINANCIAMENTO DO SISTEMA}

O Banco Nacional de Habitação, de acôrdo com a Lei número 5.107, de 13-9 -66, ficou com a função de gestor do Fundo de Garantia do Tempo de Serviço. O FGTS é constituido por recursos provenientes de descontos compulsórios feitos sôbre as fôlhas de pagamento dos empregados de tôdas as emprêsas brasileiras, depositados na rêde bancária particular, em contas bloqueadas. São garantidos aos depositários do Fundo a correção monetária e os juros dos depósitos, o que exige sua aplicação para garantir a necessária rentabilidade.

As aplicações dêsses recursos são feitas na área da construção civil, propiciando mais empregos, novas indústrias e atendimento do programa habitacional do govêrno.

Estima-se que o FGTS contará, entre arrecadação e aplicação, anualmente, com cêrca de $\mathrm{NCr} \$ 1.000$ milhões. Sem planos exeqüiveis de desenvolvimento local êsses reçursos não poderão ser aplicados e não terão a rentabilidade exigida pelos compronissos já referidos. Sòmente os planos de desenvolvimento local poderão fornecer as diretrizes para dimensionamento das obras e serviços urbanos. 


\section{OBJETIVOS DO IBRAPLAN}

Os objetivos do IBRAPLAN se concentram num programa de preparação de recursos humanos para os Escritórios de Planejamento Integrado, em colaboração com o Plano Nacional de Desenvolvimento. Sua situação em Brasília dá-lhe dimensão nacional. A ecologia humana de Brasília permite uma concentração de talentos de excepcional experiência em áreas subdesenvolvidas de gabarito internacional. De Brasília a ação de IBRAPLAN se estenderá aos 9 pólos de desenvolvimento (Pôrto Alegre, Curitiba, São Paulo, Guanabara, Belo Horizonte, Salvador, Recife, Fortaleza e Belém) e às 200 Regióes-Programa estabelecidas pelo Ministério do Planejamento. Das Regiões-Programa se estenderão as atividades de planejamento a todos os municipios brasileirus, de acôrdo com as peculiaridades locais.

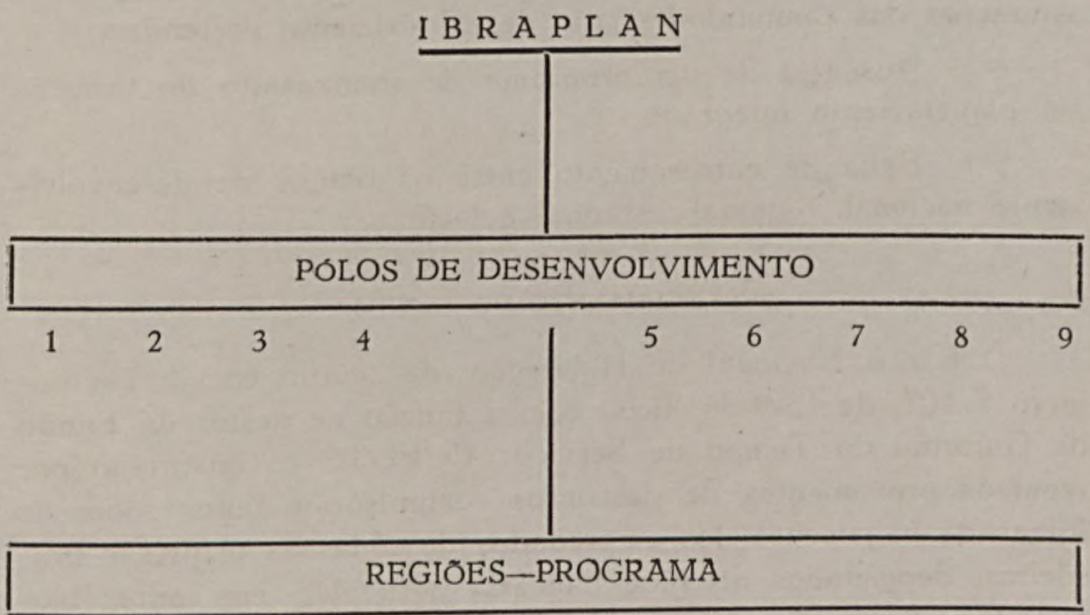

\section{MUNICIPIOS}

Não havendo possibilidade de se atacar programa de tal vulto de modo global, como é óbvio, torna-se necessário selecionar um pólo de desenvolvimento e concentrar nêle a ação do IBRAPLAN. Pela análise que fizemos, é fácil verificar que, no momento, dois Estados oferecem as condições institucionais ao desenvolvimento de um programa de planejamento integrado - São Paulo e Rio Grande do Sul. Pelas suas características sócio-econômicas, entretanto, São Paulo representa o pólo de desenvolvimento ideal para a programação que estamos projetando. 